\title{
Degree Splitting of Heronian Mean Graphs
}

\author{
S. S. Sandhya ${ }^{1}$, E. Ebin Raja Merly ${ }^{2}$ \& S. D. Deepa ${ }^{3}$ \\ ${ }^{1}$ Department of Mathematics, Sree Ayyappa College for Women, Chunkankadai, India \\ ${ }^{2}$ Department of Mathematics, Nesamony Memorial Christian College, Marthandam, India \\ ${ }^{3}$ Research Scholar, Nesamony Memorial Christian College, Marthandam, India \\ Correspondence: S. D. Deepa, Research Scholar, Nesamony Memorial Christian College Marthandam, India. E-mail: \\ christodeepadit@gmail.com
}

Received: August 18, 2016 Accepted: September 2, 2016 Online Published: September 26, 2016

doi:10.5539/jmr.v8n5p48 URL: http://dx.doi.org/10.5539/jmr.v8n5p48

\begin{abstract}
In this paper, we prove Heronian Mean labeling of some degree splitting graphs. Already we have proved Heronian Mean labeling for some standard graphs. Here we prove that degree splitting of Path $P_{3}$, Path $P_{4}, P_{3} \odot K_{1}, P_{2} \odot K_{1,2}, P_{2} \odot K_{1,3}$, $P_{2} \odot K_{3}$ are Heronian Mean graphs.
\end{abstract}

Keywords: Heronian Mean graph, degree Splitting graphs, union of graphs, Path.

\section{AMS Subject Classification: 05C78}

\section{Introduction}

By a graph we mean a finite undirected graph without loops or parallel edges. For all detailed survey of graph labeling, we refer to J. A. Gallian (Gallian, 2013). For all other standard terminology and notations we follow Harary (Harary, 1988). The concept of Mean labeling was introduced in (Somasundaram \& Ponraj, 2003). The concept of Harmonic Mean labeling was introduced in (Somasundaram, Ponraj, \& Sandhya). The concept of Harmonic Mean labeling on Degree Splitting graph was introduced in (Sandhya, Jeyasekharan, \& David). Motivated by the above results and by the motivation of the authors we study the Heronian Mean labeling on Degree Splitting graphs. Heronian Mean labeling was introduced in (Sandhya, Merly, \& Deepa) and the Heronian Mean labeling of some standard graphs was proved in (Sandhya, Merly, \& Deepa).

We shall make frequent references to the definitions and theorems that are useful for our present study. $\mathbf{A}$ Path $\mathbf{P}_{\mathbf{n}}$ is a walk in which all the vertices are distinct.

\section{Definition 1.1:}

A graph $\mathbf{G}=(\mathbf{V}, \mathbf{E})$ with $\mathrm{p}$ vertices and q edges is said to be a Heronian Mean graph if it is possible to label the vertices $\mathbf{x} \in \mathbf{V}$ with distinct labels $\mathbf{f}(\mathbf{x})$ from $\mathbf{1}, \mathbf{2}, \ldots, \mathbf{q}+\mathbf{1}$ in such a way that when each edge $\mathbf{e}=\mathbf{u v}$ is labeled with,

$$
\mathbf{f}(\mathbf{e}=\mathbf{u v})=\left\lceil\frac{\mathbf{f}(\mathbf{u})+\sqrt{\mathbf{f}(\mathbf{u}) \mathbf{f}(\mathbf{v})}+\mathbf{f}(\mathbf{v})}{3}\right\rceil(\mathbf{O R})\left\lfloor\frac{\mathbf{f}(\mathbf{u})+\sqrt{\mathbf{f}(\mathbf{u}) \mathbf{f}(\mathbf{v})}+\mathbf{f}(\mathbf{v})}{3}\right\rfloor
$$

then the edge labels are distinct. In this case $\mathbf{f}$ is called a Heronian Mean labeling of G.

\section{Definition 1.2:}

Let $\mathrm{G}=(\mathrm{V}, \mathrm{E})$ be a graph with $V=S_{1} \cup S_{2} \cup \ldots . \cup S_{t} \cup T$, Where each $S_{i}$ is a set of vertices having atleast two vertices and $T=V-\cup S_{i}$. The degree splitting graph of $\mathrm{G}$ is denoted by $\mathrm{DS}(\mathrm{G})$ and is obtained from $\mathrm{G}$ by adding vertices $w_{1}, w_{2}, \ldots . w_{t}$ and joining $w_{i}$ to each vertex of $S_{i}(1 \leq i \leq t)$. The graph $\mathrm{G}$ and its degree splitting graph $\mathrm{DS}(\mathrm{G})$ are given in figure: 1 . 


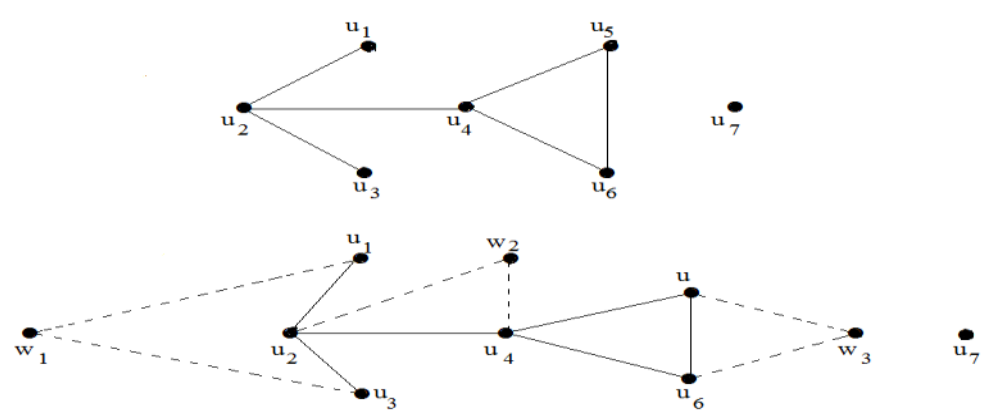

Figure 1.

\section{Definition 1.3:}

The union of two graphs $G_{1}=\left(V_{1}, E_{1}\right)$ and $G_{2}=\left(V_{2}, E_{2}\right)$ is a graph $G=G_{1} \cup G_{2}$ with vertex set $V=V_{1} \cup V_{2}$ and the edge set $E=E_{1} \cup E_{2}$.

Theorem 1.4: Any Path $P_{n}$ is a Heronian mean graph.

\section{Remark 1.5:}

Any graph $\mathrm{G}$ is a subgraph of $\mathrm{DS}(\mathrm{G})$. If $\mathrm{G}$ has atleast two vertices, then $\mathrm{G}$ contains atleast two vertices of the same degree. Hence $G=K_{1}$ is the only graph such that $\mathrm{G}=\mathrm{DS}(\mathrm{G})$.

Remark 1.6:

If $\mathrm{G}$ is regular, then $\mathrm{DS}(\mathrm{G})=G+K_{1}$.

\section{Main Results}

\section{Theorem 2.1:}

$n D S\left(P_{3}\right)$ is a Heronian mean graph.

Proof:

The graph $\operatorname{DS}\left(P_{3}\right)$ is shown in figure:2

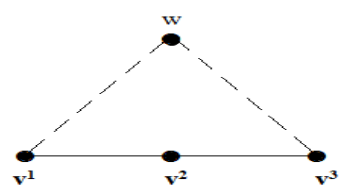

Figure 2.

Let $G=n D S\left(P_{3}\right)$. Let the vertex set of $\mathrm{G}$ be $V=V_{1} \cup V_{2} \cup \ldots \cup V_{n}$,

Where $\left.V=\left\{V_{i}{ }^{1}, V_{i}{ }^{2}, V_{i}{ }^{3}, w_{i} / 1 \leq i \leq n\right\}\right\}$ is the vertex set of $i^{\text {th }}$ copy of $\operatorname{DS}\left(P_{3}\right)$

Define a function $f: V(G) \rightarrow\{1,2, \ldots . q+1\}$ by

$$
\begin{gathered}
f\left(V_{i}{ }^{1}\right)=4 i-3,1 \leq i \leq n \\
f\left(V_{i}{ }^{2}\right)=4 i-2,1 \leq i \leq n \\
f\left(V_{i}^{3}\right)=4 i-1,1 \leq i \leq n \\
f\left(w_{i}\right)=4 i, 1 \leq i \leq n
\end{gathered}
$$

Then the edges are labeled with

$$
\begin{aligned}
& f\left(V_{i}^{1} V_{i}^{2}\right)=4 i-3,1 \leq i \leq n \\
& f\left(V_{i}^{2} V_{i}^{3}\right)=4 i-1,1 \leq i \leq n
\end{aligned}
$$




$$
\begin{gathered}
f\left(V_{i}{ }^{1} w_{i}\right)=4 i-2,1 \leq i \leq n \\
f\left(V_{i}{ }^{3} w_{i}\right)=4 i, 1 \leq i \leq n
\end{gathered}
$$

Hence by definition $1.1, \mathrm{G}$ is a Heronian mean graph.

Example 2.2: Heronian mean labeling of $4 D S\left(P_{3}\right)$ is shown in figure 3.
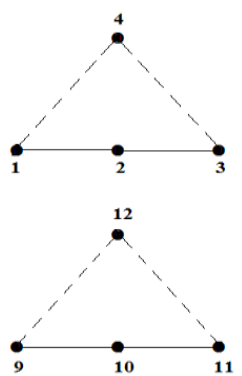
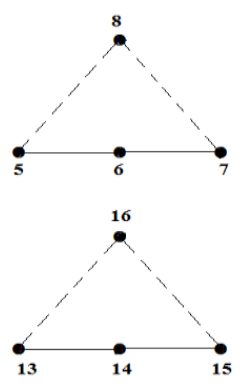

Figure 3.

\section{Theorem 2.3:}

$n D S\left(P_{4}\right)$ is a Heronian mean graph.

\section{Proof:}

The graph $D S\left(P_{4}\right)$ is shown in figure 4.

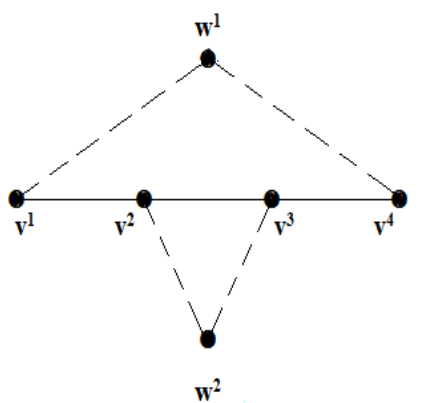

Figure 4.

Let $G=n D S\left(P_{4}\right)$. Let the vertex set of $\mathrm{G}$ be $V=V_{1} \cup V_{2} \cup \ldots . \cup V_{n}$,

Where $V=\left\{V_{i}{ }^{1}, V_{i}{ }^{2}, V_{i}{ }^{3}, V_{i}{ }^{4}, w_{i}{ }^{1}, w_{i}{ }^{2} / 1 \leq i \leq n\right\}$ is the vertex set of $i^{\text {th }}$ copy of $D S\left(P_{4}\right)$

Define a function $f: V(G) \rightarrow\{1,2, \ldots . q+1\}$ by

$$
\begin{gathered}
f\left(V_{i}{ }^{1}\right)=7 i-5,1 \leq i \leq n \\
f\left(V_{i}{ }^{2}\right)=7 i-3,1 \leq i \leq n \\
f\left(V_{i}{ }^{3}\right)=7 i-1,1 \leq i \leq n \\
f\left(V_{i}{ }^{4}\right)=7 i-4,1 \leq i \leq n \\
f\left({w_{i}}^{1}\right)=7 i-6,1 \leq i \leq n \\
f\left(w_{i}{ }^{2}\right)=7 i, 1 \leq i \leq n
\end{gathered}
$$

Then the edges are labeled with

$$
\begin{aligned}
& f\left(V_{i}^{1} V_{i}^{2}\right)=7 i-4,1 \leq i \leq n \\
& f\left(V_{i}{ }^{2} V_{i}^{3}\right)=7 i-2,1 \leq i \leq n \\
& f\left(V_{i}^{3} V_{i}^{4}\right)=7 i-3,1 \leq i \leq n
\end{aligned}
$$




$$
\begin{gathered}
f\left(V_{i}{ }^{1} w_{i}{ }^{1}\right)=7 i-6,1 \leq i \leq n \\
f\left(V_{i}{ }^{2} w_{i}{ }^{2}\right)=7 i-1,1 \leq i \leq n \\
f\left(V_{i}{ }^{3} w_{i}{ }^{2}\right)=7 i, 1 \leq i \leq n \\
f\left(V_{i}{ }^{4} w_{i}{ }^{1}\right)=7 i-5,1 \leq i \leq n
\end{gathered}
$$

Hence by definition 1.1, G is a Heronian mean graph.

Example 2.4: Heronian mean labeling of $4 D S\left(P_{4}\right)$ is shown in figure 5.
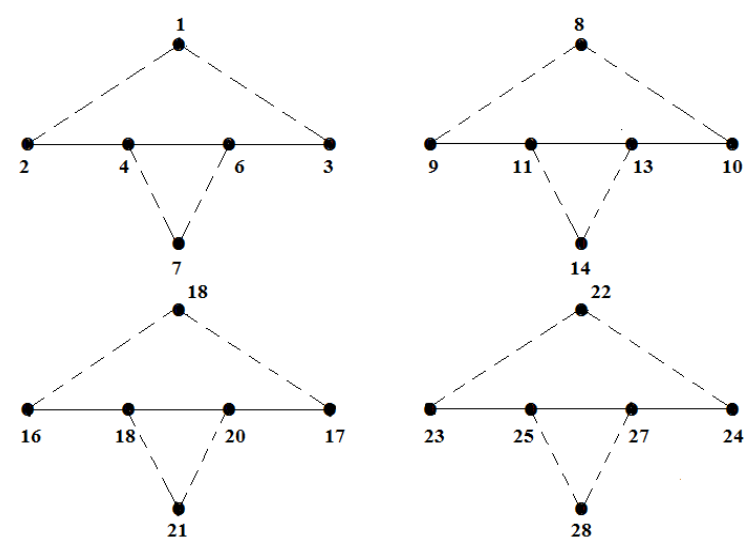

Figure 5.

\section{Remark 2.5:}

We know that $P_{2} \odot K_{1}=P_{4}$. Hence using theorem:2.3, $n D S\left(P_{2} \odot K_{1}\right)$ is a Heronian mean graph.

\section{Theorem 2.6:}

$n D S\left(P_{3} \odot K_{1}\right)$ is a Heronian mean graph.

\section{Proof:}

The graph $D S\left(P_{3} \odot K_{1}\right)$ is shown in figure:6

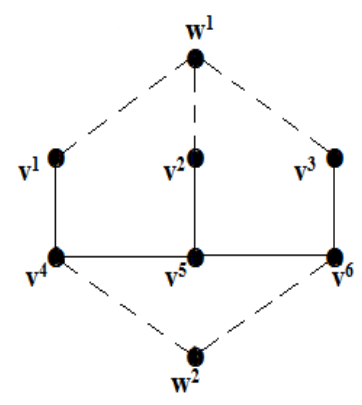

Figure 6.

Let $G=n D S\left(P_{3} \odot K_{1}\right)$. Let the vertex set of $\mathrm{G}$ be $V=V_{1} \cup V_{2} \cup \ldots \cup V_{n}$,

Where $V=\left\{V_{i}{ }^{1}, V_{i}{ }^{2}, V_{i}{ }^{3}, V_{i}{ }^{4}, V_{i}{ }^{5}, V_{i}{ }^{6}, w_{i}{ }^{1}, w_{i}{ }^{2} / 1 \leq i \leq n\right\}$ is the vertex set of $i^{\text {th }}$ copy of $D S\left(P_{3} \odot K_{1}\right)$

Define a function $f: V(G) \rightarrow\{1,2, \ldots . q+1\}$ by

$$
\begin{aligned}
& f\left(V_{i}{ }^{1}\right)=10 i-3,1 \leq i \leq n \\
& f\left(V_{i}{ }^{2}\right)=10 i-2,1 \leq i \leq n \\
& f\left(V_{i}{ }^{3}\right)=10 i-1,1 \leq i \leq n
\end{aligned}
$$




$$
\begin{aligned}
& f\left(V_{i}^{4}\right)=10 i-8,1 \leq i \leq n \\
& f\left(V_{i}^{5}\right)=10 i-5,1 \leq i \leq n \\
& f\left(V_{i}{ }^{6}\right)=10 i-6,1 \leq i \leq n \\
& f\left(w_{i}{ }^{1}\right)=10 i-6,1 \leq i \leq n \\
& f\left({w_{i}}^{2}\right)=10 i-9,1 \leq i \leq n
\end{aligned}
$$

Then we get distinct edge labels from $\{\mathbf{1 , 2}, \ldots, \mathbf{q}\}$ Hence $\mathrm{G}$ is a Heronian mean graph.

Example 2.7: Heronian mean labeling of $4 D S\left(P_{3} \odot K_{1}\right)$ is shown in figure 7.

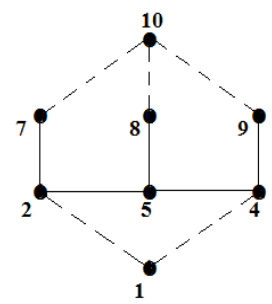

30

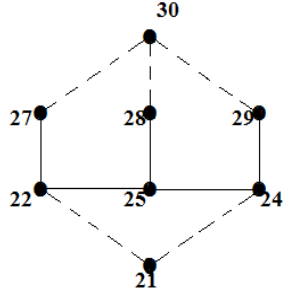

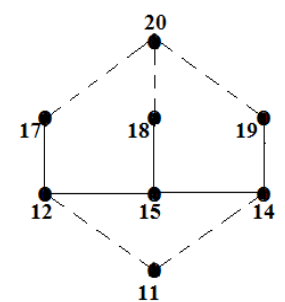

40

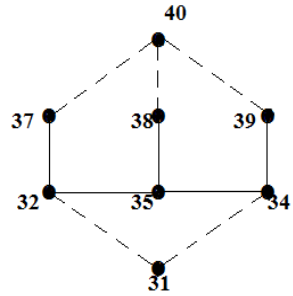

Figure 7.

\section{Theorem 2.8:}

$n D S\left(P_{2} \odot K_{1,2}\right)$ is a Heronian mean graph.

\section{Proof:}

The graph $D S\left(P_{2} \odot K_{1,2}\right)$ is shown in figure:8

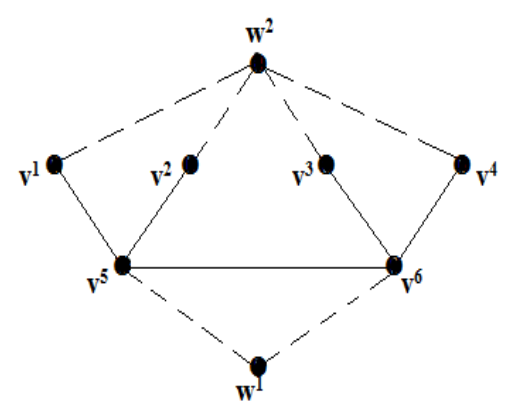

Figure 8.

Let $G=n D S\left(P_{2} \odot K_{1,2}\right)$. Let the vertex set of $\mathrm{G}$ be $V=V_{1} \cup V_{2} \cup \ldots . \cup V_{n}$, Where $V=\left\{V_{i}{ }^{1}, V_{i}{ }^{2}, V_{i}{ }^{3}, V_{i}{ }^{4}, V_{i}{ }^{5}, V_{i}{ }^{6}, w_{i}{ }^{1}, w_{i}{ }^{2} / 1 \leq i \leq n\right\}$ is the vertex set of $i^{\text {th }}$ copy of $D S\left(P_{2} \odot K_{1,2}\right)$

Define a function $f: V(G) \rightarrow\{1,2, \ldots . q+1\}$ by $f\left(V_{i}{ }^{1}\right)=11 i-5,1 \leq i \leq n$

$$
\begin{aligned}
& f\left(V_{i}^{2}\right)=11 i-3,1 \leq i \leq n \\
& f\left(V_{i}^{3}\right)=11 i-2,1 \leq i \leq n
\end{aligned}
$$




$$
\begin{gathered}
f\left(V_{i}^{4}\right)=11 i-1,1 \leq i \leq n \\
f\left(V_{i}^{5}\right)=11 i-8,1 \leq i \leq n \\
f\left(V_{i}^{6}\right)=11 i-6,1 \leq i \leq n \\
f\left(w_{i}{ }^{1}\right)=11 i, 1 \leq i \leq n \\
f\left(w_{i}{ }^{2}\right)=11 i-10,1 \leq i \leq n
\end{gathered}
$$

Then we get distinct edge labels from $\{\mathbf{1 , 2}, \ldots, \mathbf{q}\}$ Hence $\mathrm{G}$ is a Heronian mean graph.

Example 2.9: Heronian mean labeling of $4 D S\left(P_{2} \odot K_{1,2}\right)$ is shown in figure 9.
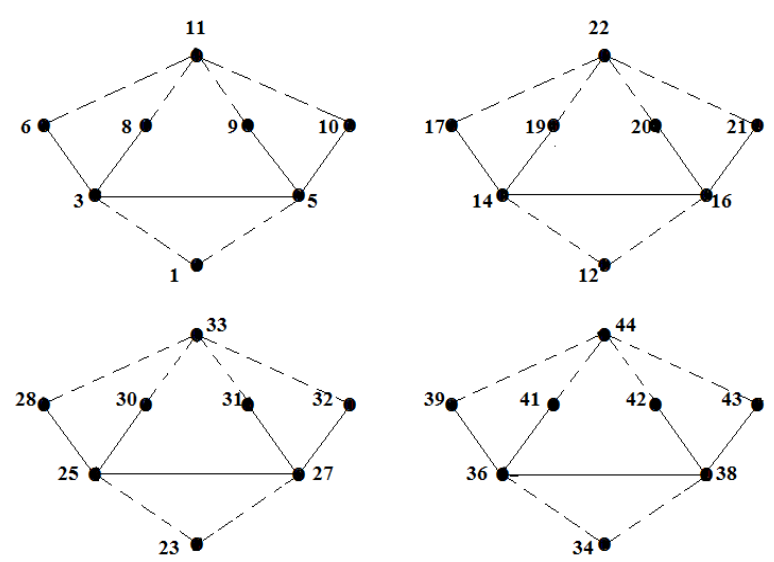

Figure 9.

\section{Theorem 2.10:}

$n D S\left(P_{2} \odot K_{1,3}\right)$ is a Heronian mean graph.

\section{Proof:}

The graph $D S\left(P_{2} \odot K_{1,3}\right)$ is shown in figure: 10

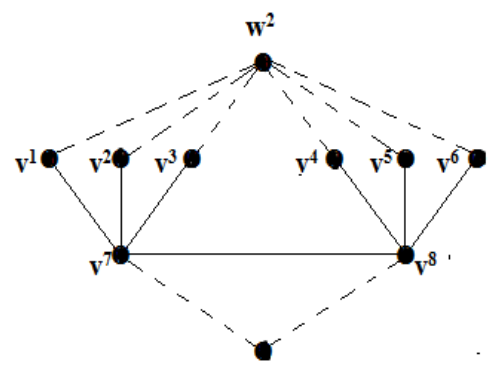

$\mathbf{w}^{1}$

Figure 10.

Let $G=n D S\left(P_{2} \odot K_{1,3}\right)$. Let the vertex set of $\mathrm{G}$ be $V=V_{1} \cup V_{2} \cup \ldots \cup V_{n}$,

Where $V=\left\{V_{i}{ }^{1}, V_{i}{ }^{2}, V_{i}{ }^{3}, V_{i}{ }^{4}, V_{i}{ }^{5}, V_{i}{ }^{6}, V_{i}{ }^{7}, V_{i}{ }^{8}, w_{i}{ }^{1}, w_{i}{ }^{2} / 1 \leq i \leq n\right\}$ is the vertex set of $i^{\text {th }}$ copy of $D S\left(P_{2} \odot K_{1,3}\right)$ Define a function $f: V(G) \rightarrow\{1,2, \ldots . q+1\}$ by

$$
\begin{aligned}
& f\left(V_{i}{ }^{1}\right)=15 i-9,1 \leq i \leq n \\
& f\left(V_{i}{ }^{2}\right)=15 i-7,1 \leq i \leq n \\
& f\left(V_{i}{ }^{3}\right)=15 i-6,1 \leq i \leq n
\end{aligned}
$$




$$
\begin{gathered}
f\left(V_{i}^{4}\right)=15 i-5,1 \leq i \leq n \\
f\left(V_{i}^{5}\right)=15 i-3,1 \leq i \leq n \\
f\left(V_{i}^{6}\right)=15 i-1,1 \leq i \leq n \\
f\left(V_{i}{ }^{7}\right)=15 i-2,1 \leq i \leq n \\
f\left(V_{i}{ }^{8}\right)=15 i-10,1 \leq i \leq n \\
f\left(w_{i}{ }^{1}\right)=15 i-14,1 \leq i \leq n \\
f\left(w_{i}{ }^{2}\right)=15 i, 1 \leq i \leq n
\end{gathered}
$$

Then we get distinct edge labels from $\{\mathbf{1}, \mathbf{2}, \ldots, \mathbf{q}\}$ Hence $\mathrm{G}$ is a Heronian mean graph.

Example 2.11: Heronian mean labeling of $4 D S\left(P_{2} \odot K_{1,3}\right)$ is shown in figure 11.
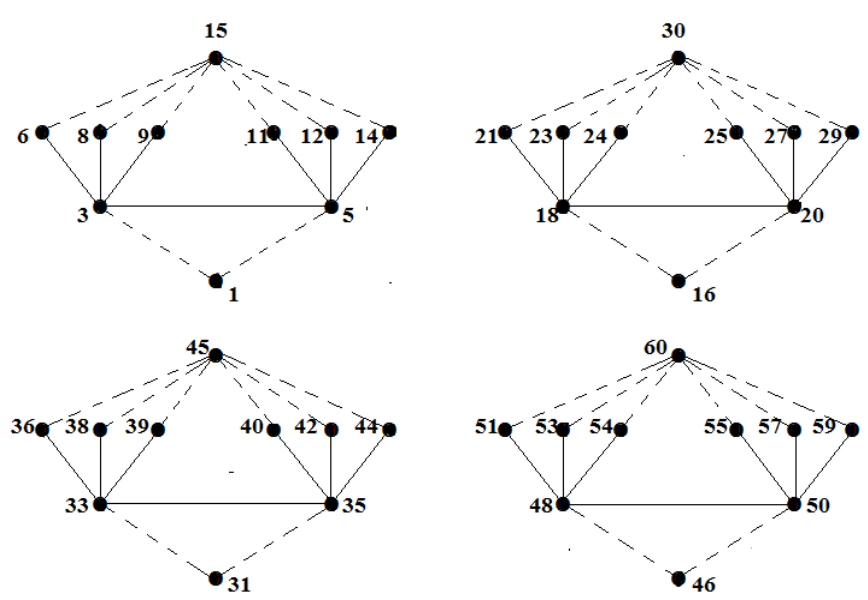

Figure 11.

\section{Theorem 2.12:}

$n D S\left(P_{2} \odot K_{3}\right)$ is a Heronian mean graph.

\section{Proof:}

The graph $D S\left(P_{2} \odot K_{3}\right)$ is shown in figure:12

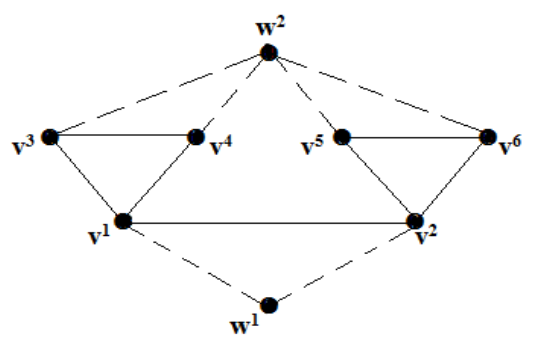

Figure 12.

Let $G=n D S\left(P_{2} \odot K_{3}\right)$. Let the vertex set of $\mathrm{G}$ be $V=V_{1} \cup V_{2} \cup \ldots \cup V_{n}$,

Where $V=\left\{V_{i}{ }^{1}, V_{i}{ }^{2}, V_{i}{ }^{3}, V_{i}{ }^{4}, V_{i}{ }^{5}, V_{i}{ }^{6}, w_{i}{ }^{1}, w_{i}{ }^{2} / 1 \leq i \leq n\right\}$ is the vertex set of $i^{\text {th }}$ copy of $D S\left(P_{2} \odot K_{3}\right)$

Define a function $f: V(G) \rightarrow\{1,2, \ldots . q+1\}$ by $f\left(V_{i}{ }^{1}\right)=13 i-10,1 \leq i \leq n$

$$
\begin{aligned}
& f\left(V_{i}{ }^{2}\right)=13 i-8,1 \leq i \leq n \\
& f\left(V_{i}{ }^{3}\right)=13 i-7,1 \leq i \leq n
\end{aligned}
$$




$$
\begin{gathered}
f\left(V_{i}^{4}\right)=13 i-5,1 \leq i \leq n \\
f\left(V_{i}^{5}\right)=13 i-3,1 \leq i \leq n \\
f\left(V_{i}^{6}\right)=13 i-1,1 \leq i \leq n \\
f\left(w_{i}{ }^{1}\right)=13 i-12,1 \leq i \leq n \\
f\left(w_{i}{ }^{2}\right)=13 i, 1 \leq i \leq n
\end{gathered}
$$

Then we get distinct edge labels from $\{\mathbf{1}, \mathbf{2}, \ldots, \mathbf{q}\}$ Hence $G$ is a Heronian mean graph.

Example 2.13: Heronian mean labeling of $4 D S\left(P_{2} \odot K_{3}\right)$ is shown in figure 13.
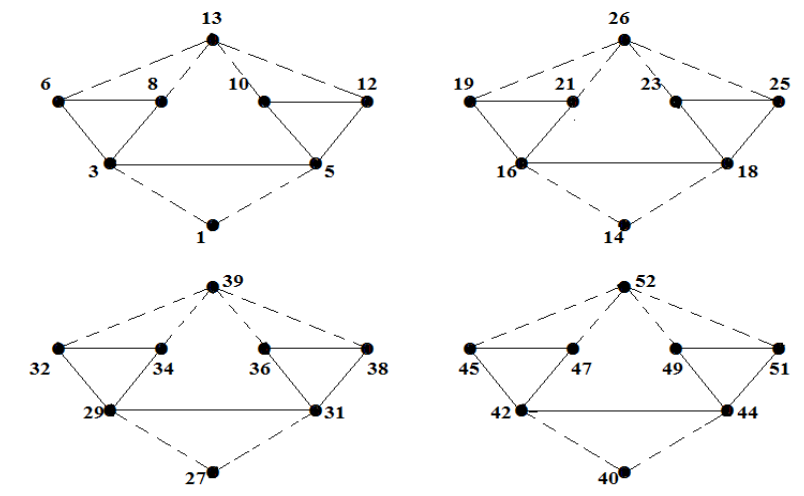

Figure 13.

\section{Conclusion}

In this paper, we studied the degree splitting behavior of some standard Heronian mean graphs. The authors are of the opinion that the study of Heronian mean labeling of degree splitting graphs will lead to newer and different results.

\section{Acknowledgement}

The authors are thankful to the referee for their valuable comments and suggestions.

\section{References}

Gallian, J .A. (2013). A Dynamic Survey of Graph Labeling. The Electronic Journal of combinatorics.

Harary. F (1988). Graph Theory. Narosa publishing House, New Delhi.

Somasundaram, S., \& Ponraj, R. (2003). Mean Labeling of graphs. National Academy of Science Letters, 26, 210-213.

Somasundaram, S., Ponraj, R. \& Sandhya, S. S. Harmonic Mean Labeling of Graphs. Communicated to Journal of Combinatorial Mathematics and Combinatorial Computing.

Sandhya, S. S., Merly E. E. R., \& Deepa, S. D. Heronian Mean Labeling of Graphs. Communicated to International Journal of Mathematical Form.

Sandhya, S. S., Merly E. E. R., \& Deepa, S. D. Some Results on Heronian Mean Labeling of Graphs. communicated to Journal of Discrete Mathematical Sciences and Cryptography.

Sandhya, S. S., Jeyasekharan, C., \& David, R. C. Harmonic Mean Labeling of Degree Splitting Graph. Communicated to Bulletin of Pure and Applied Sciences-Mathematics.

\section{Copyrights}

Copyright for this article is retained by the author(s), with first publication rights granted to the journal.

This is an open-access article distributed under the terms and conditions of the Creative Commons Attribution license (http://creativecommons.org/licenses/by/4.0/). 